\title{
Hydraulic performance of abrupt outlet transition structure with strip guide vanes at subcritical flow
}

\author{
Jaafar Maatooq ${ }^{1, *}$, and Zainab Zghaier ${ }^{1}$ \\ ${ }^{1}$ Building and Construction Dept., University of Technology, Baghdad, Iraq
}

\begin{abstract}
For some stream structures such as barrages, regulators, as well as change of channel cross section, the downstream expansion transitions structures are the common requirement. Eddies, as a result of the flow separation in such structures leads to destruction the bed and sides of the downstream channel. Head loss, on the other hand, produced through the expansion is important because it affects the stage at downstream. This study is restricted to developing the hydraulic performance of abrupt outlet transition at subcritical flow for both decreasing the head losses besides spreading the flow transversely to achieve regular velocity across the width as much as possible. New appurtenances, is adopting to install at specified configuration into a sudden transition. The appurtenances consisted of two successive rows of thin plates used as guide vanes to direct and spread the flow across the width with more uniformity. The guide vanes also keep the head losses at minimum possible. This attempt, through the results, proved that it has considerable hydraulic and economic advantages as compared to using a flared wall. Greater uniformity in velocity distributions of flow across the width, shorter length, and $70 \%$ lesser head loss are the results of the hydraulic performance of abrupt expansion transition equipped with two sets of strip vanes as compared to that with the plain one.
\end{abstract}

\section{Introduction}

When a change of channel shape, a variation of bed elevation, contraction, or expansion of channel width occurs, the transition structure becomes essential to provide a continuous link. Such changes are often required in natural and artificial channels at inlet and outlet structures, syphons, aqueducts, weirs, falls, bridges, barrages, etc. This paper has relevance only to abrupt expansive transitions for subcritical flow. When the flow sections tend to expansive, the flow tends to separate while subjected to the positive pressure gradient associated with flow deceleration, thus resulting in a considerable loss of energy [4]. As a consequence of this separation the eddies are forms adjacent to the boundaries. The present study involves the design of an expansive transition in rectangular open-channel sections at subcritical flow. The design aims are the flow expands with short transition length associated with minimum head loss. The transverse spreading of flow with more uniform distribution to prevent a jet from concentrating at one side wall or at the center is also the major aim of the study. $[1,4,9,11]$ all had agreed when subcritical flow passes through an expansion transition there is an increase in pressure associated with decrease in velocity, which means a conversion from kinetic to potential energy. [11], used a triangle baffles as appurtenances to divide the incoming flow into two parts to reduce the deflection in energy conversion. [1], developed the model by adding two sets of triangular baffles, but in both types of researches, significant eddies occur behind the model. The recommendations proposed by the previous studies in this field are used as a start to develop the model of present study.

\section{Dimensional analysis}

The first step to perform this experimental work is to determine the parameters that have governed influences on hydraulic performance. Dimensional analysis is the most useful tool in experimental fluid mechanics, allowing for the implicit formulation of criteria for dynamic similarity in a simple and direct manner. A prerequisite to run a model with suitable dimensions and boundaries of the experimental work is a proper design of such model with assumptions for magnification length, width, depth, and angle. For the condition of expansion transition structure, the following parameters influencing the hydraulic performance can be grouped and listed herein;

A- Geometrical properties:

y1- water depth at upstream of the transition (L) 
B1-channel width before transition (L)

B2- channel width after transition (L)

B- Flow properties:

V1- flow velocity at upstream section $\left(\mathrm{LT}^{-1}\right)$

E1- Specific energy of flow at upstream (L)

E2- Specific energy of flow at downstream (L)

g- Acceleration due to gravity $\left(\mathrm{L} \mathrm{T}^{-2}\right)$

C- Fluid properties:

$\rho$ - Mass density of the flowing liquid $\left(\mathrm{ML}^{-3}\right)$

$\mu$ - Fluid dynamic viscosity $\left(\mathrm{ML}^{-1} \mathrm{~T}^{-1}\right)$

The energy of flow at the end of transition will be in dependence with aforementioned parameters; thereby the functional relationship is as follows:-

$$
E 2=f(E 1, \rho, \mu, g, V, y 1, B 1, B 2)
$$

The Buckingham $\pi$ - theorem is used to create the dimensionless parameters by taking $\rho, \mathrm{V} 1$, and $\mathrm{y} 1$ as repeating variables. Elimination and delimitation, permit the terms to be restatee as:

$$
H_{L} / y 1=f(F r, B 1 / y 1, B 2 / B 1)
$$

In which the $\mathrm{HL}=\mathrm{E} 1-\mathrm{E} 2$. The physical significance of the above parameters visualized that; a head loss is related to inlet water depth (HL/y1), Fr represents a Froude number, and the terms (B1/y1) and (B2/B1) are representing the aspect ratio and the expansion ratio respectively.

\section{Experimental setup and procedure}

The investigation was made on an abrupt expansion in a laboratory flume to develop an outlet transition profile. The approach channel of width, $10 \mathrm{~cm}$, and length, $4 \mathrm{~m}$ was constructed of Plexiglas and placed at an upstream portion. Then the headwalls normal to the direction of flow are provided as a sudden expansion to the flume with a width, $30 \mathrm{~cm}$. A tail gate was given at the downstream end of the flume for flow depth regulation. Fig.1, illustrate the model as adopted in the study. Water circulation was continued by a centrifugal pump mounted beneath the flume, lifting water from the floor reservoir tanks running parallel to flume, top of which was used for providing access walk way to the working section. The discharge ranged between $2 \mathrm{~L} / \mathrm{s}-19 \mathrm{~L} / \mathrm{s}$ was diverted to the flume via an electromagnetic flowmeter, and its value was recorded directly on a digital control panel.

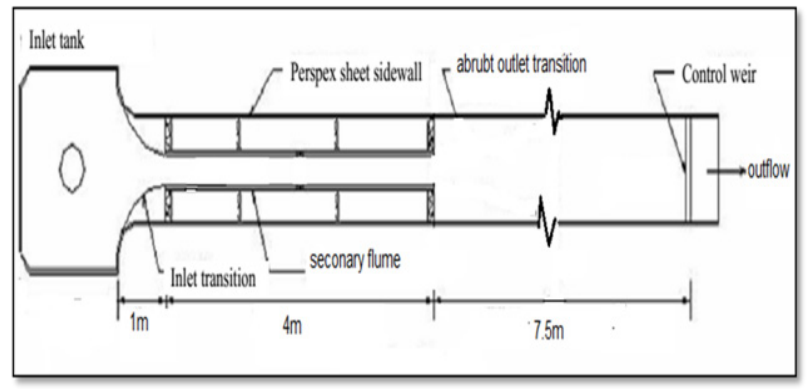

(a) Top view of flume

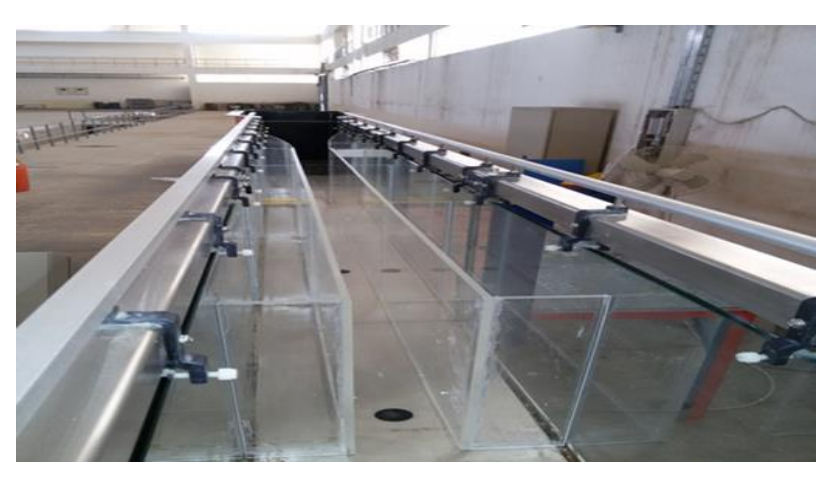

(b) The flume and abrupt outlet model

Fig. 1. Schematic representation and view of model undertaken

To test the transition model, Steps that were followed to find a significant model agreeably accomplished are:

Two sets of vanes have been used, the first set sited at $0.5 \mathrm{~B} 1$ from inlet of transition section and the other set was fixed at 1B1. These locations have been selected by the recommendation provided by [1].

The primary length of each vane was used as recommended by [1] and equal to $0.25 \mathrm{~B} 1$. The strip vane angle with the flow was $30^{\circ}$ as recommended [9]. The trial procedure was used to establish logic and recommendations during searching attempts. The data were collected for a section located at $25 \mathrm{~cm}$ upstream of expansion and for six sections within the expansion at which the flow depths and local velocities were measured via point gauge and propeller current meter respectively. The local velocity was measured at $0.6 y$ from the water surface to representing depth average velocity of the section at this point. The velocity for each station $\mathrm{X}$ and $\mathrm{Z}$ denoted as ( $\mathrm{Vxz}$ ) was measured at $0.1 \mathrm{~b}$, $0.25 \mathrm{~b}, 0.5 \mathrm{~b}, 0.6 \mathrm{~b}, 0.75 \mathrm{~b}, 0.8 \mathrm{~b}$ and $0.9 \mathrm{~b}$ laterally as shown in Fig.2. Whereas, this velocity was measured vertically from water surface at, $0.2 \mathrm{y}, 0.4 \mathrm{y}, 0.6 \mathrm{y}$ and $0.8 \mathrm{y}$. All vertical measurements of velocity were at stations along transition center line. 


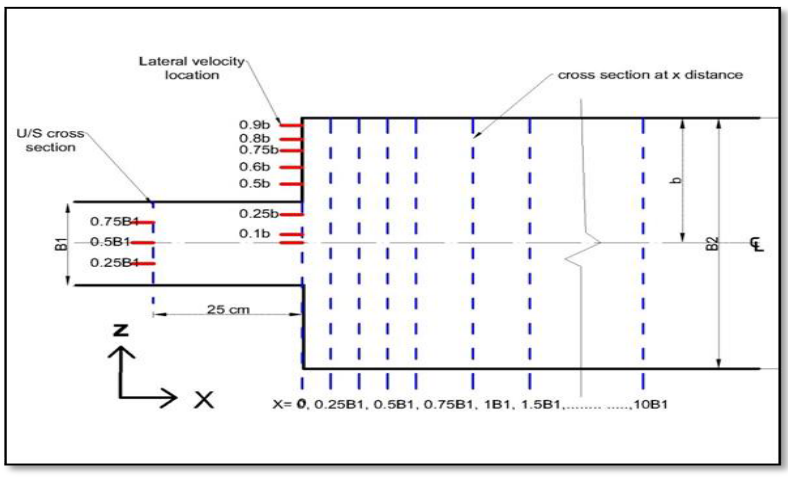

(a) Measurement sections and lateral positions to collect data (XZ) directions

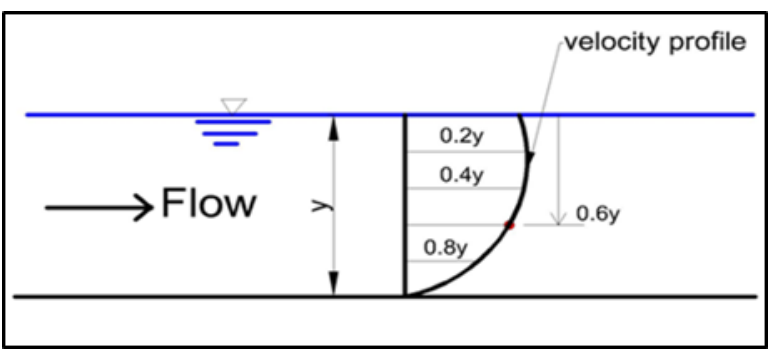

(b) Measuring positions at $y$-direction (vertically)

Fig. 2. Measurement sections and positions for $\mathrm{X}, \mathrm{Y}$ and $\mathrm{Z}$ directions

The transition was tested for two expansion ratios $\mathrm{B} 2 / \mathrm{B} 1=2.5$ and 3 . For each expansion ratio experiments were conducted at three different aspect ratios $\mathrm{B} 1 / \mathrm{y} 1=$ $0.71,1$ and 1.42. The Froude number F1, at the entrance of transition, were $0.3,0.5$, and 0.7 for each aspect ratio.

\section{Design and development transition model}

Many recommendations of previous researches and data analysis outputs have been reviewed, and some of higher relevance have been used as the initial attempt for present work to design a significant model with practical effect on flow separation and velocity distribution taking energy losses into consideration. Accordingly; the present model was intended as recommended by the previous studies in this field e.g.; $[9,1,11]$. In the present work, development was made by introducing the stripe vanes as a flow guide by which the inflow divided into three parts, two for sides and one direct along the center. Many trials conducted during the investigation synchronized with changing the limitations of previous researchers. For the first run of the initial design, as shown in Fig.3, a significant separation occurs because of the unsuitability of both the dividing of flow by the first set of the vanes and length of each vane, thereby; the development becomes necessary. If changing the spacing between the strips in the second set that led to no effect on the center flow where, it is responsible for separation phenomenon. Thus, a second trial was conducted by changing the length of the vanes, spacing, and the configuration of installation. The procedure of the second trial was replayed for each strip length checked during the investigation. On the other hand, the changing of strip angle has been adopted according to its effect on flow separation. As a result, the final design was unfolded as displayed in Fig.4.

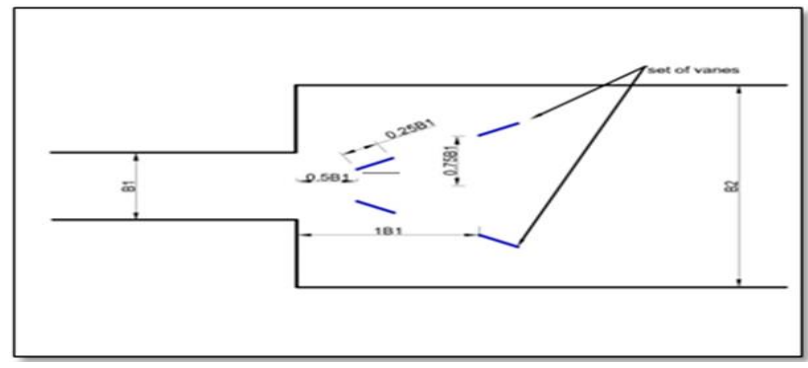

Fig. 3. Top view of primary design of model

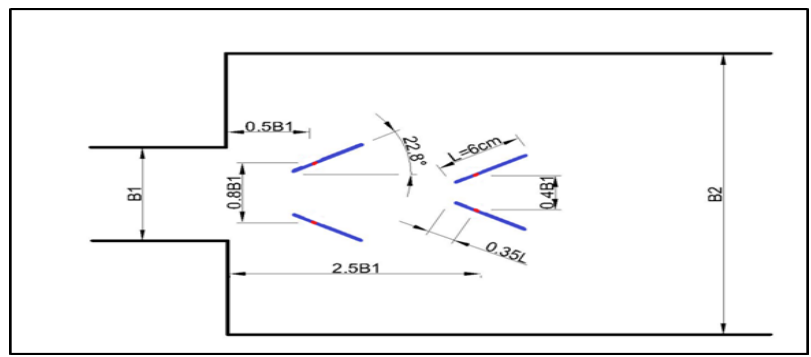

(a) Final design details sketch

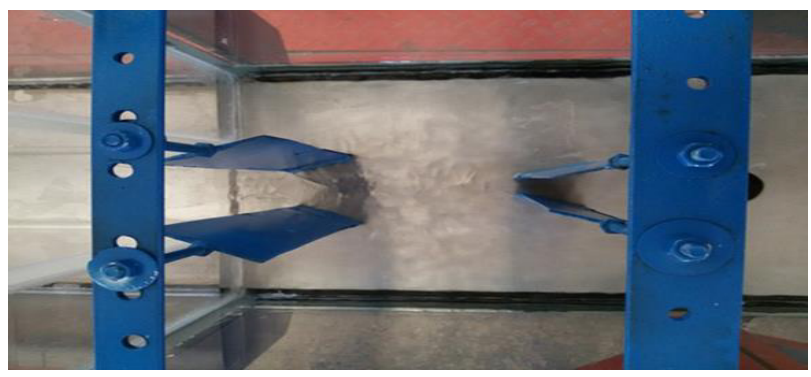

(b) Top view of final design and installation

Fig. 4. Final design, configuration, and installation of strip vanes

All sets made individually from galvanized steel stripes gage $18(0.002 \mathrm{~m}$ thickness $)$ as adopted by most researchers e.g., [10]. The preparing of these model pieces at the aforementioned configuration and dimensions needs a precise manufacturing equipment, necessary facilities, and technician. Accordingly, the models made by using Computer Numeric Control (CNC) machine. 


\section{Results, analysis and discussion}

The collected data was analyzed to show the hydraulic performance pertinent for abrupt outlet transition with strip vanes model compared with conventional shape structures (plain structure). The performance indicators adopted in the present research were the velocity distribution, head loss, and water surface profile. The profile obtained from setting up the strip vanes model on abrupt expansion structure. Using the two flow dividers with a flare angle induced to eliminate the separation and the chances of eddy formation to the less significant amount. Also, transition length ended shorter even before model's length ended and which refers to the dual action of the present model as a distributor and guide reaction with the whole performance.

The current transition (Model C) is tested for performance and compared with the straight wall transition at $22.5^{\circ}$ flare angle, which is commonly used in the field, here named as model B. Also the abrupt transition without appurtenances (plain structure) named as model A was tested as a base of performance. Fig. 5 illustrates the variation of transverse velocity distribution at selected sections within a transition for the three models. The good performance related to the uniformity of velocity distribution besides a decrease in its local values was distinguished with using model $\mathrm{C}$. However, long separation reach and concentrated on one side have been corresponded with both models A and B. Moreover, the less transition length at more uniformity in spreading along with less value of local velocity was significantly recorded with model C. The data of Fig. 5 were collected at expansion ratio equal to 3 , aspect ratio equal to 1 with $\mathrm{Q}=5.50 \mathrm{~L} / \mathrm{s}$, so that Froude number at the entrance was 0.55 for all models undertaken.

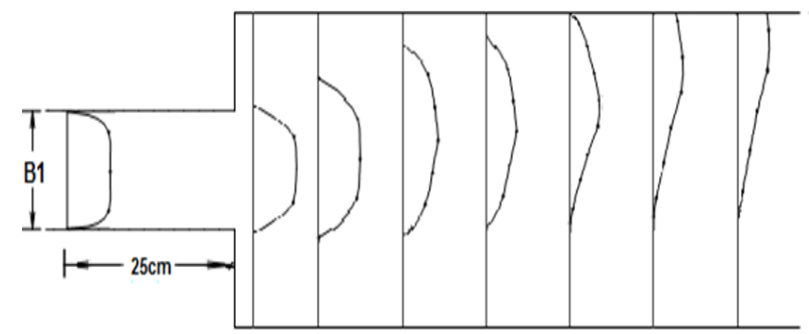

(a)

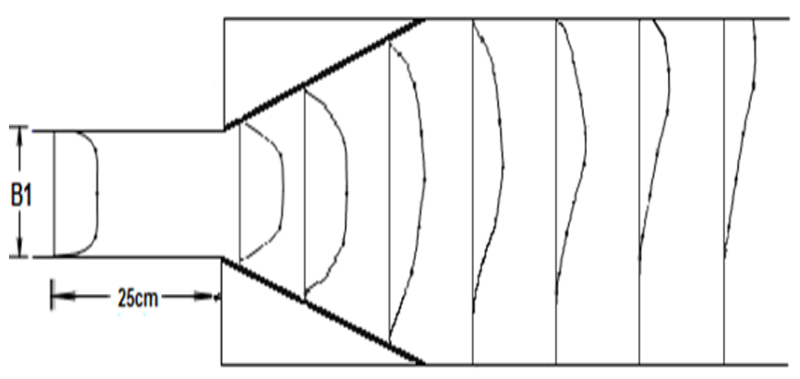

(b)

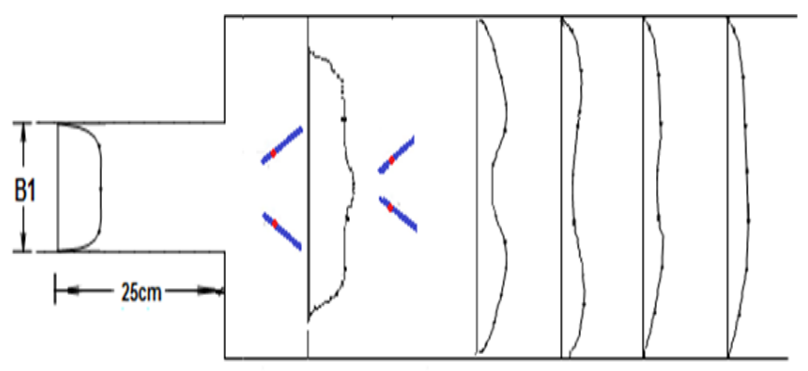

(c)

Fig. 5. Velocity distributions across the width and along the length of A, B and C models of transitions

For expansion ratio, $\mathrm{B} 2 / \mathrm{B} 1=3$, the greater reduction in head loss was recorded when $\mathrm{Fr}=0.55$ with model $\mathrm{C}$ basis on model A as compared with model B under the same flow conditions. This behavior refers to generate an inverse influential reaction by strips on flow. Thus, this influence reduces the action of eddies which are produced in A and B models. This phenomenon leads to an appreciable increase in losses. On the other hand for expansion ratio at 2.5 , the advantage of the reduction in head loss gradually decreases associated with the increasing of Froude numbers which make it the main parameter in this expansion ratio. Generally, head losses recorded for vanes model are less than that for abrupt and competing values for $22.5^{\circ}$ models at all Froude number bounded by the present study. The data listed in Table 1 illustrates this behavior, while the percentage of the difference in head losses between model $\mathrm{C}$ and model $\mathrm{A}$ and that between model $\mathrm{C}$ and model $\mathrm{B}$ are listed in the last two columns, respectively. 
Table 1. Overall head losses data collected for all models of the study

\begin{tabular}{|c|c|c|c|c|c|}
\hline $\mathbf{B 2} / \mathbf{B} 1$ & $\mathbf{B 1} / \mathbf{y} \mathbf{1}$ & $\mathbf{Q}\left(\mathbf{m}^{\mathbf{3}} / \mathbf{s}\right)$ & $\mathbf{F r}$ & $\begin{array}{c}\text { HL1 (van) } \\
(\mathbf{m})\end{array}$ & $\begin{array}{c}\text { HL2 } \\
\text { (abrupt) } \\
(\mathbf{m})\end{array}$ \\
\hline $\mathbf{2 . 5}$ & 0.71 & 0.0079 & 0.3 & 0.000601 & 0.001489 \\
\hline $\mathbf{2 . 5}$ & 0.71 & 0.01317 & 0.5 & 0.004922 & 0.008694 \\
\hline $\mathbf{2 . 5}$ & 0.71 & 0.01844 & 0.7 & 0.014421 & 0.021018 \\
\hline $\mathbf{2 . 5}$ & 1 & 0.00469 & 0.3 & 0.000202 & 0.000596 \\
\hline $\mathbf{2 . 5}$ & 1 & 0.00781 & 0.5 & 0.001204 & 0.004207 \\
\hline $\mathbf{2 . 5}$ & 1 & 0.01094 & 0.7 & 0.005389 & 0.012586 \\
\hline $\mathbf{2 . 5}$ & 1.42 & 0.00255 & 0.3 & $6.16 \mathrm{E}-05$ & 0.00016 \\
\hline $\mathbf{2 . 5}$ & 1.42 & 0.00425 & 0.5 & 0.000571 & 0.002122 \\
\hline $\mathbf{2 . 5}$ & 1.42 & 0.00595 & 0.7 & 0.003024 & 0.006158 \\
\hline $\mathbf{3}$ & 0.71 & 0.00574 & 0.35 & 0.001791 & 0.001594 \\
\hline $\mathbf{3}$ & 0.71 & 0.00902 & 0.55 & 0.007163 & 0.009304 \\
\hline $\mathbf{3}$ & 0.71 & 0.0123 & 0.75 & 0.020299 & 0.022777 \\
\hline $\mathbf{3}$ & 1 & 0.00347 & 0.35 & 0.000617 & 0.000716 \\
\hline $\mathbf{3}$ & 1 & 0.0055 & 0.55 & 0.003028 & 0.004587 \\
\hline $\mathbf{3}$ & 1 & 0.00743 & 0.75 & 0.00991 & 0.01288 \\
\hline $\mathbf{3}$ & 1.42 & 0.00203 & 0.35 & 0.000354 & 0.000453 \\
\hline $\mathbf{3}$ & 1.42 & 0.00319 & 0.55 & 0.001833 & 0.00271 \\
\hline $\mathbf{3}$ & 1.42 & 0.00445 & 0.75 & 0.005201 & 0.00693 \\
\hline
\end{tabular}

Table 1. (continued)

\begin{tabular}{|c|c|c|}
\hline $\begin{array}{c}\text { HL3 } \\
(\mathbf{2 2 . 5} \\
(\mathbf{m})\end{array}$ & {$\left[\frac{\mathbf{H L 1}-\mathbf{H L 2}}{\mathbf{H L 2}}\right] \%$} & {$\left[\frac{\mathbf{H L 1}-\mathbf{H L 3}}{\mathbf{H L 3}}\right] \%$} \\
\hline $\mathbf{0 . 0 0 0 9 9 6}$ & -59.6373 & -39.6586 \\
\hline $\mathbf{0 . 0 0 5 0 1 9}$ & -43.3862 & -1.9327 \\
\hline $\mathbf{0 . 0 1 3 9 4 8}$ & -31.3874 & 3.3912 \\
\hline $\mathbf{0 . 0 0 0 4 9 8}$ & -66.1074 & -59.4378 \\
\hline $\mathbf{0 . 0 0 2 1 7 4}$ & -71.3810 & -44.6182 \\
\hline $\mathbf{0 . 0 0 5 9 6}$ & -57.1826 & -9.5805 \\
\hline $\mathbf{6 . 1 6 E}-\mathbf{0 5}$ & -61.5000 & 0 \\
\hline $\mathbf{0 . 0 0 0 7 6 5}$ & -73.0914 & -25.3595 \\
\hline $\mathbf{0 . 0 0 2 8 3 4}$ & -50.8931 & 6.7043 \\
\hline $\mathbf{0 . 0 0 1 4 9 5}$ & 12.3588 & 19.7993 \\
\hline $\mathbf{0 . 0 0 8 1 3 6}$ & -23.0116 & -11.9591 \\
\hline $\mathbf{0 . 0 1 8 5 7 9}$ & -10.8794 & 9.2578 \\
\hline $\mathbf{0 . 0 0 0 6 1 7}$ & -13.8268 & 0 \\
\hline $\mathbf{0 . 0 0 4 1 9 7}$ & -33.9873 & -27.8532 \\
\hline $\mathbf{0 . 0 1 1 8 2 7}$ & -23.0590 & -16.2086 \\
\hline $\mathbf{0 . 0 0 0 3 5 4}$ & -21.8543 & 0 \\
\hline $\mathbf{0 . 0 0 2 1 2 5}$ & -32.3616 & -13.7412 \\
\hline $\mathbf{0 . 0 0 5 9 7}$ & -24.9495 & -12.8811 \\
\hline
\end{tabular}

The multi- regression has been following via Minitab15 Software to construct a deterministic equation for head loss when strip vanes are installed within the abrupt transition to a specified configuration. The data collected have been employed to the functional relationship which resulted from dimensional analysis at Eq. 2, and the following empirical formula restated after regression;

$$
\frac{H L}{y_{1}}=\frac{\left(B_{2} / B_{1}\right)^{3.55} * F r^{3.791}}{144.196 *\left(B_{1} / y_{1}\right)^{1.44}}
$$

The statistical indicators for this formula are; $\left(\mathrm{R}^{2}=0.976\right)$ and standard error of estimate $(\mathrm{S}=0.2304)$. Fig (6) represents the normal probability of collected data. The boundary conditions of application in practice are for Froude number ranging between 0.3 and 0.75 with expansion ratio not exceeding 3 .

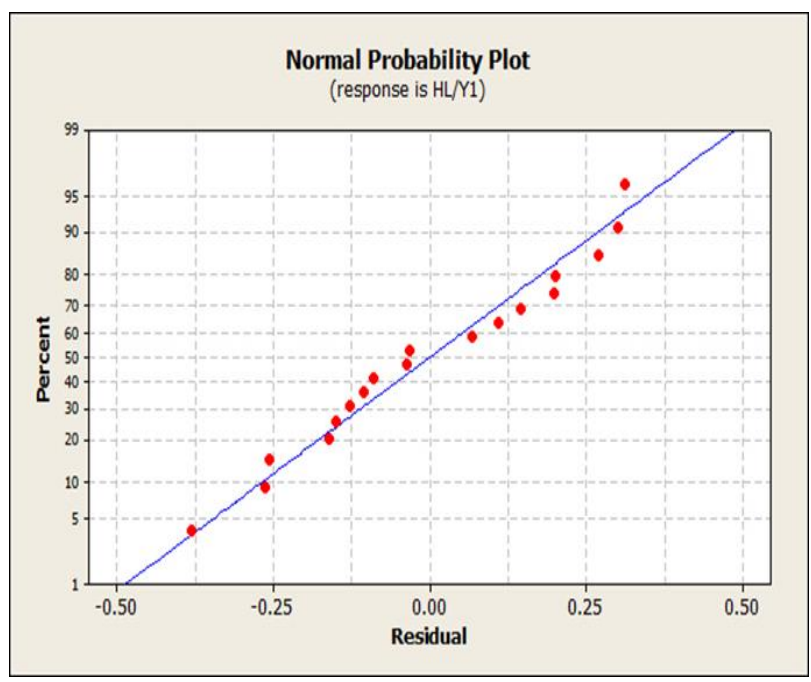

Fig. 6. Normal probability plot of data regressed

\section{Conclusions}

Through the experimental program for the present study and after analyzing the data, it can be focusing on the following conclusions:

1. New appurtenances not investigated before were adopted and installed in a specified configuration into abrupt transition.

2. The appurtenances consisted of two successive rows of thin plates used as guide vanes to direct and spread the flow across the width at more uniformity and prevent to prevent loss of more kinetic energy.

3. The hydraulic performance of the appurtenances has been evaluated, and comparisons with conventional (plain structure) proved that it has significant advantages both hydraulically and economically.

4. The experimental results showed that the abrupt transition with strip vanes becomes shorter than and induces less head losses to range between $11 \%$ and $71 \%$ less than that occurs with the abrupt plain transition.

5. The data collected have been employed to the functional relationship which resulted from dimensional analysis and a deterministic equation for head loss when strip vanes installed within the abrupt transition was restated after regression. 


\section{Notations}

The following symbols have been used in this study:

$\mathrm{B} 1=$ bed width at transition inlet.

$\mathrm{B} 2=$ bed width at transition end.

$\mathrm{Fr}=$ Froude number.

$\mathrm{g}=$ gravitational acceleration.

$\mathrm{hL}=$ head loss.

$\mathrm{L}=$ length of transition.

$\mathrm{Q}=$ discharge.

$\mathrm{b}=$ bed width at transition end $/ 2$.

$\mathrm{V}=$ velocity of flow.

$\mathrm{x}=$ longitudinal distance from inlet.

$\mathrm{y}=$ depth of flow.

$y 1=$ depth of flow at inlet.

$\mathrm{y} 2=$ depth of flow at the outlet.

$\Delta=$ difference.

The authors are grateful to the CSED/Water Resources Ministry of Iraq for approving the use of the flume and measurement facilities. Appreciation is due to a staff member of the Hydraulic Laboratory for assistance in preparing models. Deep acknowledgement is presented to Building and Construction Engineering the UOT/Baghdad for academic assistance.

\section{References}

1. Lloyd H. Austin, Gaylord V. Skogerboe and Ray S. Bennett Utah State University, 47-68 (1970)

2. Henderson, F. M., MacMillan Co., New York, N. Y., 235-250 (1966)

3. Hinds, J.,Trans., ASCE, 92, 1423-1459 (1928)

4. Alauddin, M. and Basak, B.C., J. Civil Eng. 34(2), 91101(2006)

5. Chow, V. T., McGraw-Hill, N.Y., 307-318 (1959)

6. Nashta, C.F., and Garde, R.J., J. Hy. Res., 26(1), 4965 (1988)

7. Swamee, P. K., and Basak, B. C., J. of Irrg. and Drain. Div., ASCE, 119(1), 1-17 (1993)

8. Sahar Najmeddin MASc, Civil Eng. College at Concordia Univ. Montreal, Quebec, Canada. 44-71 (2012)

9. Hyatt, M. L., M.Sc. Thesis, Utah State Univ., Logan, Utah, 46-80 (1965)

10. Novak, V. Guinot, A. Jeffrey and D. E. Reeve, Spon press, 531-581 (2010)

11. Clifford D. Smith and James N. G. Yu, J. Hy. Division, 92 (2), 1-17 (1966) 